\title{
Professionals' perceptions about healthcare resources for co-occuring disorders in Spain
}

\author{
Carlos Roncero ${ }^{1,2,3^{*}}$, Pablo Vega ${ }^{1,4}$, Jose Martínez-Raga ${ }^{1,5}$, Carmen Barral ${ }^{1,2,3}$, Ignacio Basurte-Villamor ${ }^{1,6}$, \\ Laia Rodríguez-Cintas $^{1,2}$, Beatriz Mesías ${ }^{1,4}$, Lara Grau-López ${ }^{1,2,3}$, Miguel Casas ${ }^{1,2,3}$ and Nestor Szerman ${ }^{1,6}$
}

\begin{abstract}
Background: Since provision of integrated services for patients with dual pathology or dual disorders (coexistence of an addictive disorder and other psychiatric disorders) constitutes an important challenge, this study compared the perceptions of health-care professionals with the existing, current state of specific resources for patients with dual pathology in Spain.
\end{abstract}

Methods: Epidemiological, observational, cross-sectional, multicenter study with a large, representative sample of health care professionals attending patients with dual pathology in treatment resources throughout Spain. Participants completed a specifically designed ad-hoc on-line questionnaire about their perceptions on the existence of available resources and treatment needs for patients with dual pathology. To compare professionals' perceptions with existing available resources, the same on-line questionnaire was also completed by commissioners and managers responsible for national and regional healthcare plans on drug abuse.

Results: A total of 659 professionals, mostly psychologists (43.40\%) or psychiatrists (32.93\%) agreed to participate in the study. The highest degree of concordance between the perceptions of professional and the actual situation was found regarding the existence of mental health and addiction networks (either separately or unified) (74.48\%), followed by specific workshops (73.08\%) and sub-acute inpatient units (67.38\%), specific hospitalization units (66.26\%), detoxification units (63.15\%) and outpatient programs (60.73\%). We detected a lower degree of agreement regarding specific occupational rehabilitation centers (59.34\%) day hospitals (58.93\%), day centers (57.88\%), outpatient intermediate resources (48.87\%), psychiatric acute admission units (46.54\%) and therapeutic communities (43.77\%). In addition, on average, health care professionals underestimated the number of resources present in their respective communities.

Conclusions: Relevant differences exist between the perceptions of professional and existing available resources for dual pathology patients in Spain, thus supporting the need of additional efforts and strategies to establish a registry and clearly inform about available resources for patients with dual diagnosis.

Keywords: Dual pathology, Dual disorders, Co-occurring disorders, Resources, Professionals' perception, Mental health, Drug abuse

\section{Background}

Dual pathology, dual disorders or co-occurring disorders are defined as the presence of an addictive and another mental disorder, with rates well-documented above $50 \%$ [1-14]. Dually-diagnosed patients represent a substantial proportion of individuals in treatment and commonly

\footnotetext{
* Correspondence: croncero@vhebron.net

'Sociedad Española de Patología Dual. Londres, 17 28028, Madrid, EU, Spain ${ }^{2}$ Department of Psychiatry, Outpatient Drug Clinic, Vall d'Hebron University Hospital - Public Health Agency, Barcelona (ASPB), CIBERSAM. Passeig de la Vall d'Hebrón, 119-129, 08035 Barcelona, EU, Spain

Full list of author information is available at the end of the article
}

show greater severity from both the clinical and social perspectives than individuals with solely one of the disorders [15]. Importantly, dual disorders are usually associated with a significantly worse clinical course and outcome, as well as with a poorer treatment response and adherence, than patients with one of the disorders alone [15-17], as well as with frequent, high levels of polymedication [18]. Failure to detect, diagnose and adequately treat patients with dual pathology can jeopardize their chances of success [19]. 
Implementation of specific services and resources for dual pathology represents an important challenge [13,19]. Traditionally, mental health and addiction treatment services have worked sequentially or in parallel, resulting in low adherence of dually diagnosed patients to treatment and in an inadequate management of the common interrelated problems of the comorbidity $[17,20,21]$.

Specific integrated resources are being currently developed for patients with dual pathology (such as in- and outpatient units, or day centers). The integrated model envisages a global treatment plan for both mental health disorders and substance abuse disorders, being provided in one time by a multidisciplinary treatment team. Shared treatment plans, as "integrated model" implicates, would minimize philosophical differences among care providers. Substance abuse and psychiatric illnesses are accurately diagnosed and targeted for a stage-specific treatment [15]. In Spain, special resources have developed (including acute inpatient dual diagnosis units; dual diagnosis residential communities; dual diagnosis programs in both mental health and drug user treatment outpatients centers) to move into a final integrated model of treatment [15].

However, to date few studies, focused in professionals' evaluation about co-occurring resources, have assessed the implementation of these strategies for dually diagnosed patients [22-25]. In a recent epidemiological, observational, cross-sectional, multicenter study conducted in Spain with a sample of healthcare professionals managing patients with co-occurring disorders, according to the perceptions of professionals, specific healthcare resources for co-occurring disorders were clearly insufficient, with scarcity of specific outpatient programs, hospitalization units, sub-acute inpatient units, outpatient intermediate resources, day hospitals and day centers [24]. In fact, the importance of the professionals' perceptions on other aspects of the disorder (such as management and long-term care) has also been recently addressed [26]. Based on these results, the need of additional efforts and strategies for treating individuals with co-morbid disorders, such as a National Plan on Drugs on co-occurring disorders was suggested [24].

The present study was designed to compare the knowledge of professionals on specific resources for co-occurring disorders.

\section{Methods}

\section{Design}

This observational, cross-sectional, multicenter study was conducted in Spain between February and May 2011 with a representative sample of 659 healthcare professionals involved in the management of patients with co-occurring disorders in various treatment settings throughout Spain, in order to explore the available healthcare resources and the specific needs for patients with co-occurring disorders.

The study protocol was approved by the Ethics Committee of Hospital de la Vall d'Hebrón (Barcelona, Spain) and procedures were in accordance with the ethical standards of the Helsinki Declaration, as revised in 2000. After complete description of the study, healthcare professionals accepted to voluntarily participate, without receiving any remuneration.

\section{Questionnaire}

For this purpose, an ad-hoc on-line questionnaire (http:// www.patologiadual.es/profesional_publica.html) was designed by a group of different experts in dual diagnosis from different clinical and academic origins, including the authors of this article, and distributed on-line to the participating investigators to collect all relevant data related to specific healthcare resources for patients with co-occurring disorders (available on www.sepd.es). In addition, the questionnaire included several items to address the perceptions of the professionals on current available resources for co-occurring disorders (such as specific outpatient units and programs, hospitalization units, detoxification units, day centers, acute admission units, occupational rehabilitation programs and centers, or therapeutical communities) and resources that, in their opinion, should be made available for patients with co-occurring disorders or dual disorders. Their opinion on the integration model was also solicited. The results of this on-line questionnaire has been reported previously [24].

To compare professionals' perceptions with existing available resources, the same on-line questionnaire was also completed by commissioners and managers responsible for national and regional healthcare plans on drug abuse (between June and July 2012). The degree of agreement or concordance between professionals' perceptions and commissioners was expressed as percentages of surveyed healthcare professionals informed on the number of different resources for dual pathology.

All the members of the Spanish Society of Dual pathology (SEPD) and the professionals in the SEPD database (over $2,000)$ were sent three e-mails inviting them to complete the questionnaire. The questionnaire was also available to all the professionals working in the mental health or addiction field in Spain who accessed the SEPD website.

We assessed the general perspective of healthcare professionals from all 17 Spanish regions or Autonomous Communities. Each Autonomous Community has its own regional parliament and government, with independent health politics and general state-wide health strategies.

To compare the professionals 'perception with the available existing resources, between June and July 2012, the online questionnaire was also completed by 19 commissioners and managers responsible of the national and regional drug 
plans (17 commissioners from the regions and 2 commissioners from the autonomous cities Ceuta and Melilla). Commissioners are member boards (heads of addiction services), responsible to promote action policies in the addiction fields in the different Spanish autonomous communities or regions.

\section{Statistical analysis}

In the statistical analysis, frequency tables and percentages were obtained for categorical variables while measures of central tendency and dispersion were calculated for continuous variables (mean, Standard Deviation (SD), minimum and maximum and 95\% confidence intervals).

\section{Results}

\section{Sample characteristics}

A total of 659 healthcare professionals working throughout Spain, were recruited to participate in the study. The sample included 55\% $(\mathrm{n}=286)$ women and $45 \%(\mathrm{n}=232)$ men from 553 centers in 235 cities across Spain. 95.9\% of centers provided 1 or 2 participants, $2.6 \%$ provided 3 participants, $0.7 \%$ provided 4 participants, while only a $0.04 \%$ provided 7 participants.

The majority of the sample was of Spanish origin $(n=625$, 94.8\%). The rest of study participants were Latin American $(\mathrm{n}=22 ; 3.3 \%)$, from other European countries $(\mathrm{n}=8$; $1.2 \%)$ and a small proportion $(n=4 ; 0.6 \%)$ of other origins. Most of the participants were psychologists $(43.40 \%)$ or




psychiatrists (32.93\%), followed by general practitioners (14.57\%) and physicians with other specialist degrees (7.59\%), whilst a small percentage of professionals had two or more specialties.

In general, diagnosis of dual pathology, performed by psychiatrists, was established according to Diagnostic and Statistical Manual of Mental Disorders, Fourth Edition, Text Revision (DSM-IV-TR)-based.

Regarding network affiliations, $40.5 \%$ of participants belonged to the mental health network and $35.4 \%$ to the addictions network, while a lower percentage of participants belong to the unified network (mental health and addictions) (13.5\%) or to both separated networks (10.3\%). Only $0.3 \%$ participants were not attached to any network.

From the 19 asked commissioners, a total of 16 (84.2\%) answered the questionnaire.

\section{Knowledge on networks}

Regarding the level of knowledge on the mental health and addictions networks (existence of separated networks and/or a unified treatment network), a high degree of agreement between professionals' perceptions and commissioners' data (about 75\%) was observed (Figure 1a).

Knowledge on existing resources for co-occurring disorders.
A lower percentage of concordance (about 61\%) was found between professionals' perception and existing resources regarding the available outpatient programs for co-occurring disorders (Figure 1b). In addition, 66.26\% of participating professionals answered in agreement with the commissioners' reports on specific hospitalization units for co-occurring disorders (general adult psychiatry inpatient units intended to offer short-term hospitalization to treat, control or stabilize the individual patient) (Figure 1c).

A total of $63.15 \%$ of participating healthcare professionals provided accurate answers on the existing detoxification units accepting dually-diagnosed patients (facilities designed to offer medical evaluation and to provide medically-assisted withdrawal treatment to adult patients with dual pathology who may require pharmacological treatment to manage withdrawal symptoms from alcohol or other drugs). In contrast, only $18.41 \%$ of professionals correctly indicated the number of these units (Figure 2).

Only $46.54 \%$ of professionals were correctly informed on the existing psychiatric acute admission units for cooccurring disorders, whilst only $2.54 \%$ of these knew the correct number of this type of units available (Figure 3 ).

Study participants were also asked on the number of individual resources in each community for patients with co-occurring disorders. A total of $67.38 \%$ of surveyed healthcare professionals were aware of the existence of sub-
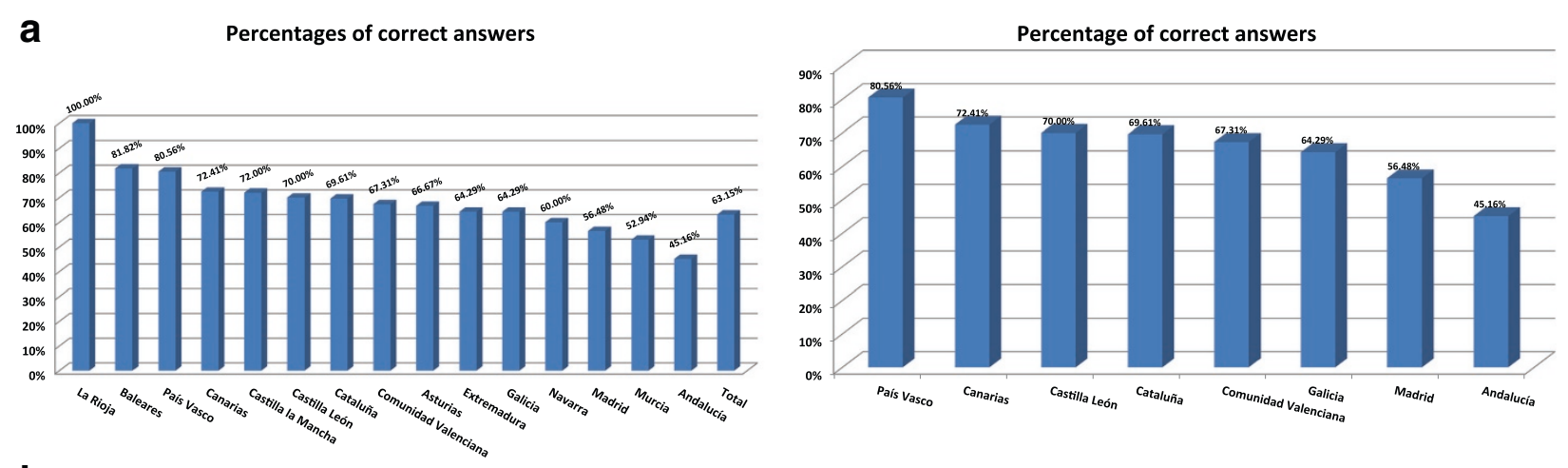

b Percentage of correct answers
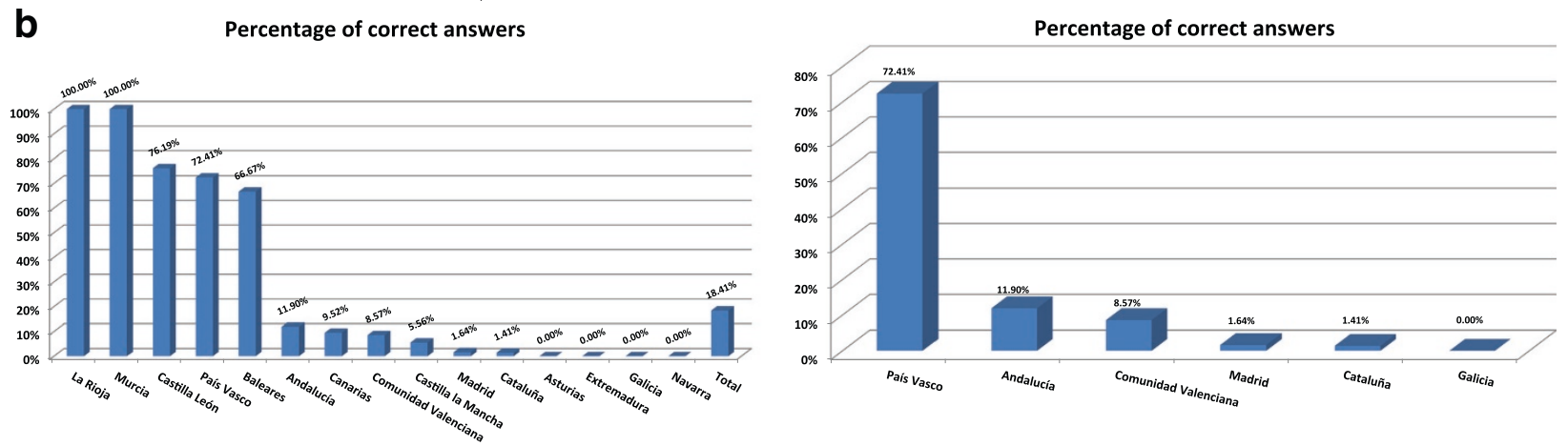

Figure 2 Knowledge on the available existing detoxification units accepting patients with dual disorder. a) Degree of knowledge on the existence of detoxification units accepting patients with dual disorder, b) Degree of knowledge on the number of detoxification units accepting patients with dual disorder. 

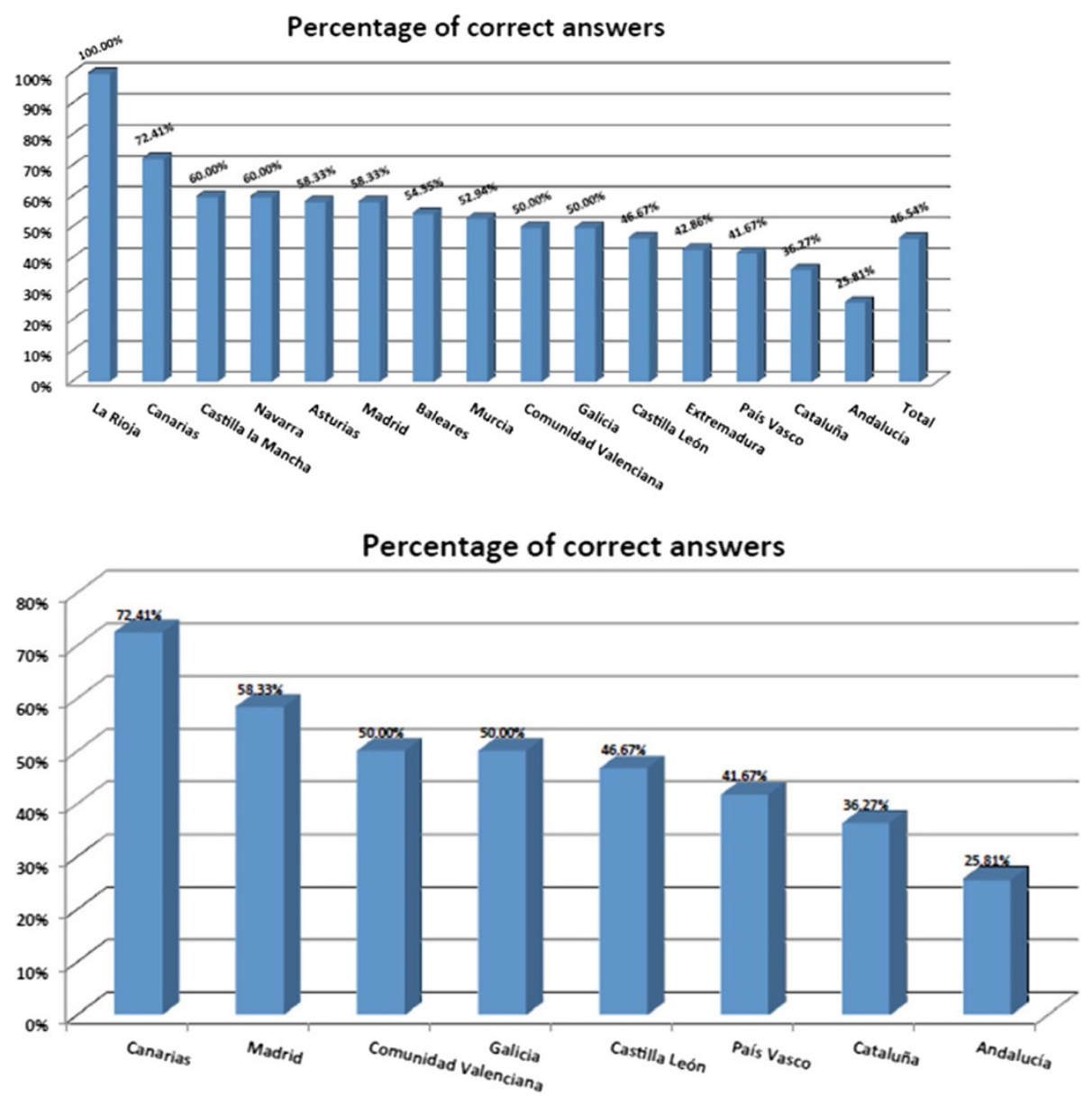

Figure 3 Knowledge on the available existing psychiatric acute admission units for patients with dual disorder.

acute inpatient units (1-3 months of inpatient stay, provided to patients with a co-occurring disorder experiencing an exacerbation or a relapse of their condition), $48.87 \%$ of outpatient intermediate resources, $58.93 \%$ of day hospitals, $57.88 \%$ of day centers, $73.08 \%$ of workshops, $59.34 \%$ of occupational rehabilitation centers and $43.77 \%$ of therapeutic communities accepting patients with dual disorders (Figure 4).

For all the different resources, in general, professionals underestimated the number of resources present in their respective communities. In particular, we found a relevant difference between the number of units offered in each community and the number believed to be available by the professionals: 4.33 vs 1.6 for sub-acute inpatient units, 28.5 vs 2.97 for outpatient intermediate resources, 7.5 vs 1.28 for day hospitals, 9 vs 1.96 for workshops, 21 vs 13.8 for day centers, 5.33 vs 2.14 for occupational rehabilitation centers and 7.2 vs 2.4 for therapeutic communities (Figure 5). Finally, we found relevant differences between the Spanish regions in all the questions.

\section{Discussion}

\section{Importance of findings}

In health-services planning and in the evaluation of healthcare needs for the provision of adequate treatment resources, opinions of healthcare professionals are generally sought by healthcare authorities, as a strategy that is receiving increasing attention in recent years [27]. However, the number of studies evaluating the perceptions of professionals on healthcare resources around the world, unfortunately, is still low.

To our knowledge, the present observational study is the first report comparing the perceptions of professionals with data on the existing available integrated resources for the management of patients with cooccurring disorders, since current data is evidencing the need of integrating services for the optimal treatment of co-morbid disorders [17,28,29]. Indeed, integrated services for dually diagnosed patients pathology face continuous challenges to find more efficient and effective strategies for improving the overall poor prognosis and 


\section{a Percentage of correct answers}

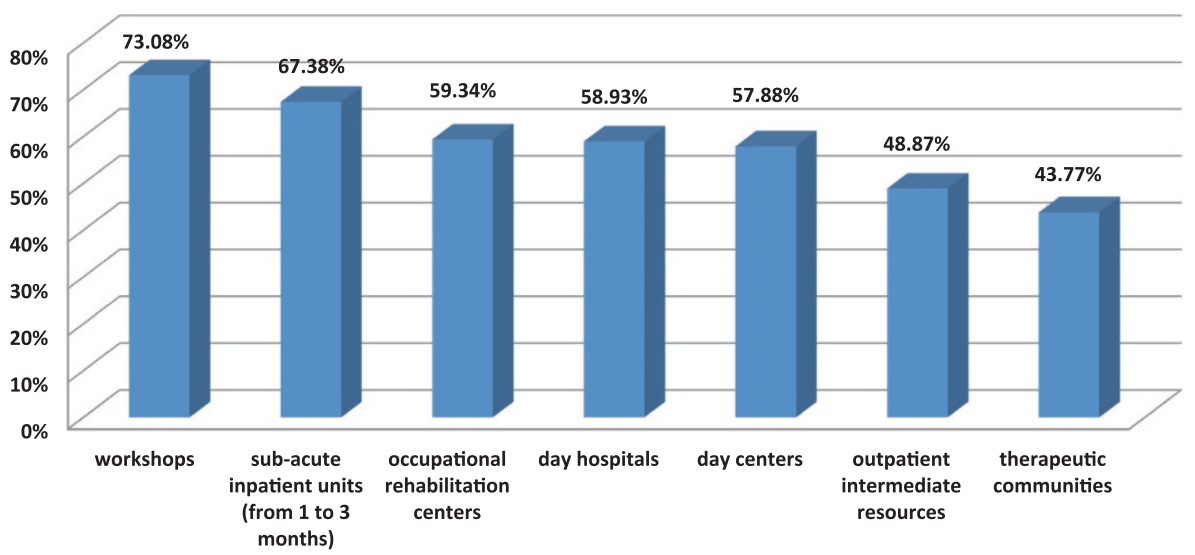

\section{b Percentage of correct answers}

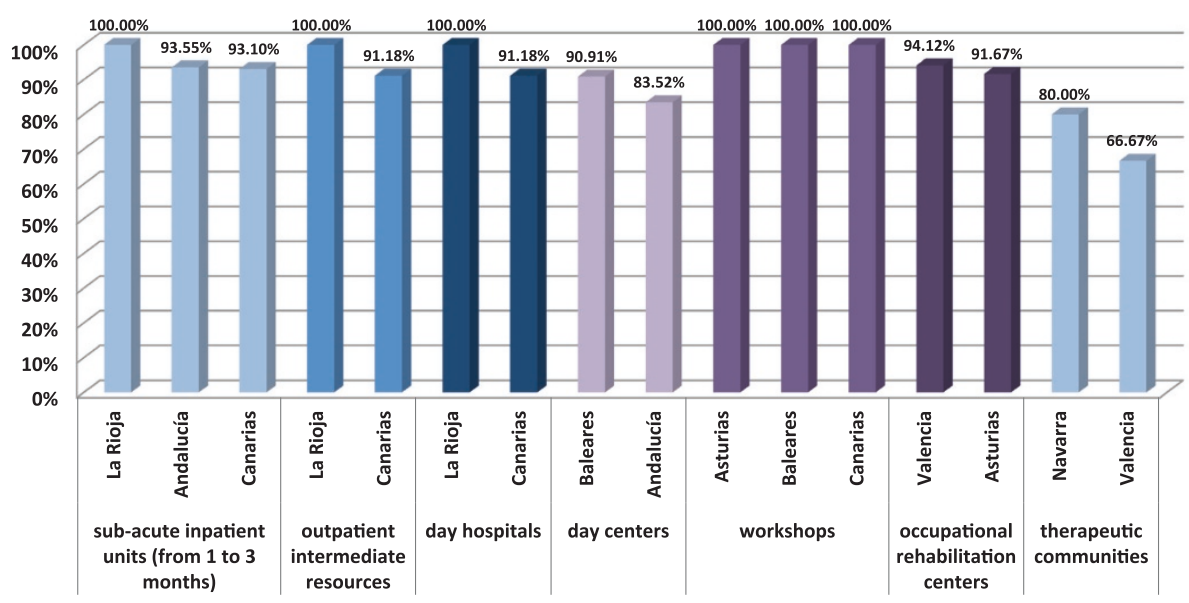

Figure 4 Professionals' perceptions on the number of resources for patients with dual pathology. a) Percentages of surveyed healthcare professionals informed on the number of different resources for dual pathology in their own autonomous community, b) Communities with the highest percentage of informed professionals about the number of resources for dual pathology.

outcomes and the rates of morbidity and mortality associated with this condition [8,10,13,16,21,28,30,31].

Previously, we reported that in Spain specific healthcare resources for the management of co-occurring disorders were clearly insufficient according to the professionals' perceptions $[13,24]$. In view of these results, we compared the perceptions of professionals with data coming from commissioners and managers responsible for the national and regional healthcare plans on drug abuse. Results obtained have evidenced the important gap between reality and professionals' perceptions on the existence of specific resources for dually diagnosed patients, with systematic underestimation of the number of the existing resources. We also noted important differences among the different Spanish regions, thus highlighting the existing diversity of professionals' knowledge on specific resources, which could be derived from the independent health politics and general state-wide health strategies of the regions. We think that the implementation of a single national register on this type of resources could avoid this reported lack of information and that information and dissemination campaigns are required to make known the available specific resources for cooccurring disorders.

Although we could not perform comparisons with any other international study, we consider these results of great relevance, since they evidence that, as a consequence of the lack of adequate knowledge by healthcare professionals, currently the available integrated resources are probably underused, thus failing to provide an optimal management of patients with co-occurring disorders. Although the causes of this lack of knowledge have not been addressed, we postulate that it can be at least partly explained by the lack of diffusion or a poor 


\section{Comparison between reality and professionals' perception}

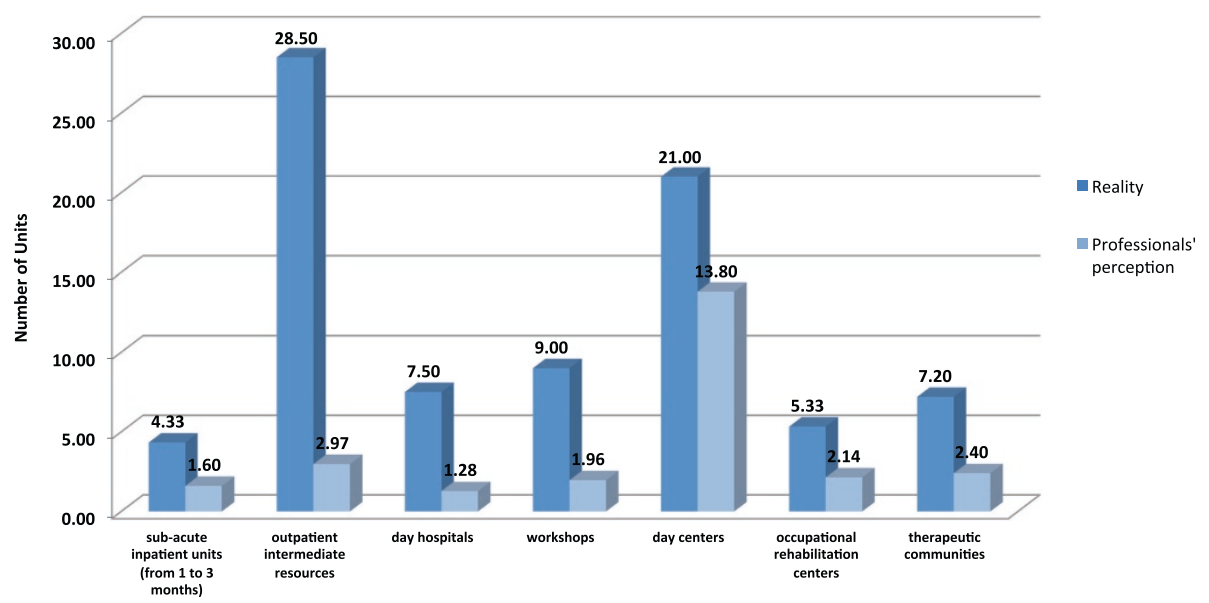

Figure 5 Comparison between existing resources and professionals' perception on the number of dual pathology units. Resources include sub-acute inpatient units, outpatient intermediate resources, day hospitals, day centers, workshops, occupational rehabilitation centers, therapeutic communities.

information flow regarding the available resources in each region.

As in other health problems that require an integrated care approach, professionals need to be aware of both local and regional network resources and specific treatment facilities available from each individual institution [32,33]. Devising a register of available integrated resources for health professionals could be a feasible option to address this issue. As proposed elsewhere, classification of local and community resources based on the treatment offered, professionals in charge, etc. could help professionals working with dually diagnosed patients to identify a quick and targeted access to available resources, according to patient needs [32,33].

\section{Limitations and strengths of the study}

In the absence of the necessary information, in the present study it is possible that some professionals could have provided incorrect answers due to having misleading information or no information at all. We believe that a register, with a correct classification of resources (integrated/non integrated), would help to revert this tendency. Among the strengths of the study, it is important to consider that this report, based on a large sample of healthcare professionals, gives for the first time, new insights into the real knowledge of professionals attending patients with co-occurring disorders on integrated resources. In fact, being known the complexity of management of these patients, assessing perceptions and knowledge of professionals is of paramount importance for the specific management of the disorder, since these professionals are responsible to select treatments, interventions and resources use [24,26].
Importantly, we consider that the surveyed sample of Spanish professionals working with co-occurring disorders patients could represent between 5-8\% of all the professionals working in the Spanish mental health or addition networks. Of note, the official data corresponding to the existing resources were obtained from the different commissioners, which are the maximum autonomic authorities in this issue.

Among the limitations of this report, we consider that it is possible that professionals participating in this study could be most interested in co-occurring disorders than the others who did not participate, thus their answers could not be representative of the total of professionals. The high percentage of respondent professionals, however, allows us to have a broad picture of the current situation, useful for treatment planning and developing adequate health policies. Further studies should assess the possible causes of the reported differences and the implementation of new strategies, such as a national register of integrated resources for co-occurring disorders.

\section{Conclusions}

Based on the results of the present study, we can conclude that relevant differences exist between the perceptions of professional and existing available resources for co-occurring disorders patients in Spain, thus supporting the need of additional efforts and strategies to register and inform about the existing resources for duallydiagnosed patients. We propose the implementation of a single national register and information and dissemination campaigns to make known the available specific resources for co-occurring disorders. 


\section{Competing interests}

The authors declare that they have no competing interest.

\section{Authors' contributions}

Participated in research design: CR, PV, JM-R, CB, IB-V, LR-C, BM, LG-L, MC, NS. Conducted experiments: JM-R, CB, IB-V, LR-C, BM, LG-L. Contributed new reagents or analytic tools: $C R, P V, N S$ : Performed data analysis: $C R, P V$, NS. Wrote or contributed to the writing of the manuscript: CR, PV, NS. All authors read and approved the final manuscript.

\section{Acknowledgements}

The study has been sponsored by an unrestricted educational grant of BrainPharma, SA, belonging to Grupo Ferrer, S.A. and has been performed with support from the Spanish "Plan Nacional sobre Drogas". The authors thank to Anna Campuzano PhD of Brainpharma, SA, belonging to Ferrer Group SA the technical support for the study development, Núria Piqué for her writing assistance and Grupo Saned, SA, for technical secretary services and for the statistical analysis.

\section{Participants' list}

Julieta Ruiz Mccormick; Arturo Argelaguer Martínez, Nuria Rigau Simon, Bartolome Marin Romero, Carlos Mizrahi Recasens, Izaskun Elortegi Kaiero, Alejandro Alfonso Sanchez Moraga, Diana Gallo Martinez, Joaquin Martinez Valente, Rafael Villanueva Blandón, Jaime Domper Tornil, Marta Torra Moreno, Carlos Chiclana Actis, Sebastián Navarro Tauste, Patricia Marqués Cabezas, Rosó Duñó Ambròs, Manuel Antonio Valencia Fernández, Laura Blasco Barrena, Raúl Padilla Soldado, Mariana Abeledo Otero, Segundo de Miguel Gimeno, Margot Garcia de Gregorio, Sebastián Mera, Maria Ruiz Gomes, Juan Manuel Ferrer Angulo, Maria Lizaur, René Miguel González Rubio, Isabel Piñel Cortes, Aquilino Cuenda Corrales, Ma Ángeles Bravo Álvarez, Maria de Guia Castro Granados, María José Alemany García, Alfredo Barredo, Juan Alday Muñoz, Paula Maria Fuertes Silva, Jose Luis Salazar Sanchez, Ivan Ollé i Llopis, Sara Morís González, Marcos López Hernández-Ardieta, Itxaso Oiarzabal Monje, Maria Suarez Gomez, Jose Antonio Wanguemert Garcia, Paula Gestoso Campos, Carmen Barral Picado, Josep Lluis Conde Sala, Adrián Neyra Del Rosariio, José Miguel Rodríguez Molina, Bayta Diaz Rodríguez, Maria Dolores Gomez Garcia, Dionisio García Osuna, Juan Francisco Torres Soto, Manuel Arrojo Romero, Raquel Ramírez Larrondo, Iria Espiño Díaz, Carmen Fernandez Cabrera, Mercedes Gómez Pérez, Rafael Tortosa Gómez, Alexandra Glink Lezana, Jose Luis Montero Horche, Lidia Toribio Martinez, Idoia Zorrilla Larrainzar, Paola Bully Garay, Olga Prieto Blanco, Ángel Gabriel Herrera Garcia, Marina Lamich, José Gabriel Franco Vásquez, Isabel Recio Aroca, Carme Mariscot Bas, Emiliano Rodriguez-Sanchez, Desiderio Mejías Verdú, Concepcion Bancalero Romero, Emilio Javier Blanco Bengoechea, Juan José Millán, Josefina Fernandez Iglesias, Sergio Ocio, Rebeca Ojea Quintela, Ana Barrera Frances, Miguel Angel Landabaso Vazquez, Francisco Acosta Artiles, Ana María Bárzano Cruz, Miquel Joan Far Ferrer, José María Salgado Cacho, David Cabrera Lucas, Irene López Romero, Rafael Rodriguez Calzada, Fidel J. García Sánchez, Rafael Gautier Roques, Nicolás Condés Balboa, Samuel Pombo Chorto, Rocio Martinez Higueras, Amable Manuel Cima Muñoz, Pilar Gardeta Sabater, Cesar Pereiro Gomez, Marta Sabio Gutierrez, Ana Fernández-Manchón García, María Martínez Diez, Carles Rodríguez i Domínguez, Valentín Estévez Pérez, Estefanía Hidalgo Aldana, Eugenia González Goizueta, Vanesa Ortiz González, Ma Trinidad Gómez Talegón, Rosa Maria Ventura Broncazo, Cristina Prieto Fernández, Antoni Far i Ferrer, Maria Jesus Longo Garcia-Peñuela, María Nieves Gómez Llano, Ana Ma Bastida de Miguel, Ma Joaquina Lloreda Morillo, Joan de Pablo Rabazo, Rafael Casas Rivera, Ana María Caaveiro García, Carlos Muñoz Pérez, Ma Dolors Mas Delblanch, Isabel Ma de Haro García, Miriam Aran, Carlos Martín Fernández-Mayoralas, Carlos Calcaño, Iban Onandia Hinchado, Rafael Casquero Ruiz, Maria Isabel Iglesias Hernandez, Belen Rubio Morell, José Luis Castro Feijóo, Carmen Pérez Espino, Sandra Castillo Magaña, Albert Batalla Cases, Maria Teresa Perez Castellano, Lorena Casete Fernández, Luis Cordero de Ciria, José B. Morales Ramirez, Leonor Riera Fueyo, Ramon Angel Rivera Mera, Antonia María Gómez Hinojosa, Pedro Massé García, Eduardo Samper Lucena, Sabela Maceda García, Blanca Castillon Abenia, Eglee Florencia Castillo Oramas, Rafael Campos Cloute, Francisco Rosagro Escámez, Purificación Reguillo Calero, Eduardo Mirón Ortega, María Luisa Gutiérrez López, David Busse Olive, Lorena Pereyra Grustan, Miguel-Angel Villalba Abarquero, Maria Dolores Romero Lemos, Margarita Ma Hernanz Manrique, Maria Pilar Elias Villanueva, Marina Gonzalez Gonzalez, Ahinara Mendo Hernández, Cristobalina Lopez Lorente, Pilar Bermejo
Gonzalez, Ma Rosa Sánchez-Waisen Hernández, Jesus Saiz Otero, Ma Yolanda P. Crespo Jiménez, Maria Gonzalez Hidalgo, Óscar Garrido Miralles, Julia García White, Joaquin Descals Gilabert, Cristina Martinez Martinez, Josep Cornellà Canals, Mar Peinado Vergara, Cristina Larrayoz Perez, Consuelo Llamazares Peña, Amaia Perez-Izaguirre Urquizu, Jorge Muñoz Ruata, Olga Arbeo Ruiz, Vicente Montero Sierra, Antonia San Martín García, Rafael Coullaut-Valera, Maria Badenes Mezquita, Izaskun Madinabeitia Cobos, Maria de Gracia Viseu Pinheiro Lopes Do Rego, Ma Soledad Iglesias Pérez, Miguel Angel Beltran Viciano, Juan Miguel Llorente Del Pozo, Juan Ramírez López, Mónica Serrano García, Victoria Panisello Sorribes., Mcarme Masferrer i Herrera, Miquel Cavalleria Verdaguer, Almudena Hermoso, Barbara Mas Corbella, Antonio García Patiño, Asun Santos Mocoroa, Luis Alfonso Núñez Domínguez, Lourdes Del Rio Garcia, Manuel Fernandez Molina, Teresa Orengo Caus, Jose Diaz Morfa, Isabel Moreno García, Beatriz Isabel Pelaez Gutierrez, Maria Asunción Berrueco Quintero, Francisco Arnau Peiró, Gonzalo Haro Cortés, Helen Dolengevich Segal, Susagna Nevado, Mireia Reyero Salazar, Yolanda Carmona Cifuentes, Eva Amada Povedano Suárez, Astrid Roda de Sola, María Del Sol Roncero Rodríguez, Diana González Cano, Amanda Rodriguez Urrutia, Vicent Balanzá Martínez, Emilia Herrero López, Manuela Reyes Requena, Noemí Vivas Rubio, Esther Garcia Usieto, Silvia Reyes Campos, Marisol Mondragon Egaña, Maria Calatayud, Miguel Guerrero Diaz, María José Casares López, Jose Manuel Martínez Delgado, Dolores Velo Camacho, Gregorio Navalon Roberto, Luis Basilio Rodríguez, Bartolomé Pérez Gálvez, Encarnacion Gomez Juarez, Alfonso Rodriguez-Palancas Palacios, Francisco Javier Arranz Estévez, Angela Rita Martín Caballero, José Luis Gómez Juárez, Estrella Fatima Rueda Aguilar, Addis Leonor de Álava Celso, José María Sánchez García, Vicente García Vicent, Ma Josefa Campillo Cascales, Isabel Rodriguez Garcia, Rezeda Radjapova, Radjapova, José Manuel Fernandez Fernandez, Miguel GómezCalcerrada Berrocal, Maria Jose Gomez Del Castillo, Karmele Garay, Irene Milla Melero, Maria Alvarez Riedweg, José Antonio Segura Zamudio, Laia Miquel de Montagut, Alfredo Gurrea Escajedo, Lurdes Ortgosa Chasco, Isabel Gonzalez Katarain, Maria Jesus Mota Rodríguez, Emilio Rato Alario, Castora Silva Silva, Alfonso Pérez Poza, Beatriz Oda Plasencia García de Diego, Rafael García Pérez, Juan Manuel Alonso Ramis, Miquel Monras Arnau, Gideoni Fusté Coetzee, Sebastian Pablo Rodríguez, Daniel Ocaña Rodríguez, Carmen Rubio Otero, Maribel Molina Fernández, Ana Adan Puig, Ana Sanchez, Juana Teresa Rodriguez Sosa, Jose Luis Alvarez Marques, Juan Manuel Miguens Tjarks, Magdalena de Miguel Fernández, Andres Perez Barrero, Maria Del Mar Lazaro Redondo, Carmen Palau Muñoz, Ana Alvarez Navares, Vicente Garijo Garcia, Maria Ines Padilla Cabrera, Sonia Encabo Franco, Silvia Funes, Ma Del Rosario Demetrio Santana, Ma Paloma Pando Fernández, Jose Juan Ávila Escribano, Belen Alonso Verdugo, Lidia Sánchez Morales, Alfred Granell Gorrochategui, Ramon Bellot Arcis, Esperanza Bosch Casañas, Juan Carlos Prados Moreno, Pedro Galindo Espada, Patricia Gracia García, Patricia Fadon Martin, Carlos José Pino Serrano, Andrés Arce, Pilar Calvo Estupiñán, Claudia Alejandra Fuentes, Juan Antonio Arance Maldonado, Elena Gómez Crespo, Rocio Caballero Campillo, Josep Oltra Aznar, Ma Amparo Ferreros Villar, Susana Rodriguez Picó, Isabel Hernandez Otero, Cristina Eloísa Masini Fernández, Ma Elena Brea Pastor, Marisa Dorado Garcia, Anna Olive Torralba, Verónica Gómez Gómez, Pedro Seijo Ceballos, Nazaret Martínez Mollinedo, María Vázquez Costa, M. Luisa Sanz Aguado, Icíar Álvarez Uría, Raquel Alvarez Garcia, Manuel Pérez Rivas, Cristina Gomez Atienza, Francisco Rodriguez Pulido, José López Delgado, Domingo Robayna Ojeda, Matias Real López, Guadalupe Lopez Cerón, Pilar San Juan, Gerard Mateu Codina, M Jose Hidalgo Quiles, Mónica Portillo Santamaría, Alejandro Ramirez Reffay, Ana Victoria Paris Fernandez, David Caceres Anillo, Olga Junca Jiménez, Miguel Angel Quintanilla Lopez, Jose Maria Vázquez Vázquez, Carmen Tosio, Nora Soria Garcia, Rafael Navarro Pichardo, Inmaculada Gutierrez Porcel, J. Luis Frias Pulido, Virginia Yera Verruga, Antonio Manuel Rodríguez Cerezo, Ma Luisa Celorrio Bustillo, Carmen Quesada Romero, Angeles Ramon Góngora, Maier Rodriguez Zabaleta, Ma Loreto Medina Garrido, David Barranca Vargas, Luis Pacheco Yañez, Juan Bosco Anguiano Jiménez, Idoia Larrañaga Garate, José María Playà Busquets, Ma Carmen Rodriguez Fernandez, Irene Aparicio Salinas, Adriana Massotti Leon, Jose Angel Alcala Partera, Jose Maria Osuna Fuentes, Jose A. Juan Berna, Maria Rosario Consuegra Sanchez, Félix Reina Galán, Ramón Martinez Remacha, Josefina Puig Campañà, Gerardo Aznar Rivera, Pilar Garzon Nacer, Juan Manuel Jiménez Lerma, Carmen Díaz Lorenzana, Juana Palacios Márquez, José Manuel Fernández Fernández, Antonio Jesús Molina Fernández, Ainhoa Garibi Perez, Joseba Pérez Atxa, Ignacio Basurte Villamar, Juan Antonio Abeijon Merchan, Blanca Carcolé Batet, Ignacio Gonzalez Jiménez, Usue Espinós Ortueta, Raquel Perez Hernandez, Silvia Amparo Navarro Ferragud, Jose Martinez Raga, Olga Chapinal Sánchez, José Miguel Cuevas, Barranquero, Iluminada Rubio García, Vicente Fabregat Navarro, Rodriguez Zarate Carlota Pilar, 
Cesar Negro Albañil, Belen Borjano, Esperanza Manzano Prado, María Lapeña Valencia, Alba de La Caridad Alba Pons, Ma Del Mar Sánchez Fernández, Antonio Teran Prieto, Fernando Gómez-Pamo Guerra Del Río, Beatriz Nogueras, Oskar Clar Corteza, Ana Romaguera Piñol, Ana Cáceres Santos, Belén Orozco Jabato, Oscar David Galera García, Ana Amelia Sánchez Padilla, Asuncion Prieto Orzanco, Juan Carlos Hornillo Castro, José Javier Rosa Mestre, Jose A. Contreras Nieves, Vicente Tomas Gradoli, Ana Aparicio Aparicio, Diego Jose Moreno Ribas, Celia Gómez Yepes, Francisco Arias Horcajadas, Amparo Lara Garcia, Ohicys Cala Hernandez, Antonio Manuel Cabrera Ibarria, Ainhoa Madoz Ibáñez, Jose Maria Blanco Loberías, Francisco Vera Izquierdo, Maria Amparo Malea Fernández, Aránzazu Ferrer Añó, Montserrat Mola Gubert, Ana María Sánchez Viñas, Graciela Adriana Gómez Albarracín, Carlos Salavera Bordás, Antonio Francisco García Atenza, Rosa María Tomé Rodríguez, Mariano Montavez Díaz, Amparo Sanchez Mañez, Maria Sales Gilabert Fos, German Jurado de Flores Yepez, José Luis Sancho Acero, Diana Bachiller Valdenebro, Juan Jose Molina Castillo, Julio Quiles Lloret, Susana Gómez Baeza, Jose Morante Del Peral, Mercedes Zurdo Carrion, Marta Pilar Jiménez Cortés, Mar Nieto Riva, Laura Elías Casado, Rafael Goya Moscoso, Joan Alvarós Costa, Carlos Martin Picola, Javier Fernández Aurrecoechea, María Soledad Olmeda García, María Isabel Calvo Ortega, Josep Antoni Ramos-Quiroga, Marc Ferrer Vinardell, Aimée María Ruiz Rodríguez, María Teresa Guillermo Pardenilla, Nicolás Amador Amador, Silvia Piñeiro Carrió, Gemma Isabel San Narciso Izquierdo, Bruno Ribeiro Do Couto, Jesus Salomon Martinez, Carmen Gimeno Escrig, Bartolomé de La Fuente Darder, Jesús V. Cobo Gómez, Pablo Cardona Pintos, Esther Ontanilla Reyes, Marina Comín Zafón, Beatriz Mesías Pérez, Gloria Cordeiro-Crespo Cabral-Campello, Isabel Lopez Escamilla, Letizia Irene Manchado Lopez, Amadeo Martinez Guevara, Jose Torroba Molina, Miriam Mayoral Morena, Ma Angeles Alonso Urbano, Enrique Marcos Gonzalez, Lluisa Pilar Puerta Marín, Andrés Martín Joison Rotbard, Roberto Pérez, Lorena Castillo Jiménez, Francisco Herrera Benitez, María Zaida Ramos Marrero, Nuria Seijas Fernández, Maria Gomez Sousa, Javier Gonzalez Gonzalez, Estela Saez Fuentes, Wilson Nieves Pla, Carmen Sanchez Rivas, Manuel Conde Amado, Alfonso Gil Martinez, Jose Martinez, Concha Fernandez Ramirez, Iñaki Markez Alonso, Javier Santamaria Gutierrez, Francisco Javier Trujillo Carrillo, Eva Giralt Martínez, Armando Santiago Masuelli, Carla Ramos Vidal, Ignacio Zaera Cuadrado, Jose Luis Navarro Gonzalez, Nieves Domeque Valiente, Miguel Del Nogal, Ma Josefa García Escudero, Juan Jesus Hernandez Gonzalez-Nicolas, Irma Teresa Bracamonte Garć́a, M. Carmen García Guijosa, Ma Fernanda Gómez Villaespesa, José Miguel Zoido Ramos, Alejandro Moreno Galindo, Juan Matias Fernandez, César Paumard Oliván, Sumpci Guillén Font, Manuel Javier Pretel Pretil, José Miguel Ausejo Sanz, Carlos Iglesias Echegoyen, Paloma Sanchez de La Nieta Aragonés, Celia Del Pino Lidón, Hugo Mongay Sanchez-Gijon, Braulio Del Palacio Lopez, Begoña de Pablo Garcia, Lucía San Narciso Izquierdo, Cesar Lucchetti, Angel Manuel Turbi Pinazo, Atahualpa Granda Flores, Juan Angel Correa de La Calle, Marta Fernandez de Aguirre Malaina, Beatriz Mesias Perez, Gustavo Molina Rodríguez, Jaime A. Fernandez Fdez, Domingo Panizo Rivas, Ma Del Pilar Moreno Palancar, Francisco Javier Sedano Pérez, Carmen Iglesias Azcue, Gerardo Hernandez Vazquez, Lucía Yolanda Armenteros García, Cristina Baliarda Hernández, Gerardo Pacheco Otoya, Marta Vallcanera Cabrera, Roberto Carlos Tapia, Juan A López-Rodríguez.

\section{Author details}

'Sociedad Española de Patología Dual. Londres, 17 28028, Madrid, EU, Spain. ${ }^{2}$ Department of Psychiatry, Outpatient Drug Clinic, Vall d'Hebron University Hospital - Public Health Agency, Barcelona (ASPB), CIBERSAM. Passeig de la Vall d'Hebrón, 119-129, 08035 Barcelona, EU, Spain. ${ }^{3}$ Department of Psychiatry and Legal Medicine, Universitat Autònoma de Barcelona, Plaça Cívica, 08193 Bellaterra (Cerdanyola del Vallès), Barcelona, EU, Spain. ${ }^{4}$ Instituto de Adicciones. C/ Juan Esplandiú, 11-13, 28007 Madrid, EU, Spain. ${ }^{5}$ Unidad Docente de Psiquiatría y Psicología Medica, Hospital Universitario Dr. Peset y Universidad de Valencia, \& Universidad CEU-UCH, 46017 Valencia, EU, Spain. ${ }^{6}$ Department of Psychiatry, Hospital Universitario Gregorio Marañón, Calle Doctor Esquerdo, 46, 28007, EU, Madrid, Spain.

Received: 12 July 2014 Accepted: 17 August 2014 Published: 28 August 2014

\section{References}

1. Regier DA, Farmer ME, Rae DS, Locke BZ, Keith SJ, Judd LL, Goodwin FK: Comorbidity of mental disorders with alcohol and other drug abuse: result from the Epidemiologic Catchment Area (ECA) study. J Am Med Assoc 1990, 264:2511-2518.

2. Kessler RC, Nelson CB, McGonagle KA, Edlund MJ, Frank RG, Leaf PJ: The epidemiology of co-occurring addictive and mental disorders: implications for prevention and service utilization. Am J Orthopsychiatry 1996, 66:17-31.

3. Weaver T, Madden P, Charles V, Stimson G, Renton A, Tyrer P, Barnes T, Bench C, Middleton H, Wright N, Paterson S, Shanahan W, Seivewright N, Ford C: Comorbidity of substance misuse and mental illness collaborative study team: comorbidity of substance misuse and mental illness in community mental health and substance misuse services. Br J Psychiatry 2003, 183:304-313.

4. Kessler RC: The epidemiology of dual diagnosis. Biol Psychiatry 2004, 56:730-737.

5. Adamson SJ, Todd FC, Sellman JD, Huriwai T, Porter J: Co-existing psychiatric disorders in a New Zealand outpatient alcohol and other drug clinical population. Aust N Z J Psychiatry 2006, 40:164-170.

6. Rush B, Koegl CJ: Prevalence and profile of people with co-occurring mental and substance use disorders within a comprehensive mental health system. Can J Psychiatr 2008, 53:810-821.

7. Pulay AJ, Stinson FS, Ruan WJ, Smith SM, Pickering RP, Dawson DA, Grant BF: The relationship of DSM-IV personality disorders to nicotine dependence- results from a national survey. Drug Alcohol Depend 2010, 108:141-145.

8. Swendsen J, Conway KP, Degenhardt L, Glantz M, Jin R, Merikangas KR, Sampson N, Kessler RC: Mental disorders as risk factors for substance use, abuse and dependence: results from the 10-year follow-up of the National Comorbidity Survey. Addiction 2010, 105:1117-1128.

9. Hasin D, Fenton MC, Skodol A, Krueger R, Keyes K, Geier T, Greenstein E, Blanco C, Grant B: Personality disorders and the 3-year course of alcohol, drug, and nicotine use disorders. Arch Gen Psychiatry 2011, 68:1158-1167.

10. Roncero C, Fuste G, Barral C, Rodríguez-Cintas L, Martínez-Luna N, EiroaOrosa FJ, Casas M: Therapeutic management and comorbidities in opiate-dependent patients undergoing a replacement therapy programme in Spain: the PROTEUS study. Heroin Addict Relat Clin Probl 2011, 13:5-16.

11. Szerman N, Lopez-Castroman J, Arias F, Morant C, Babín F, Mesías B, Basurte I, Vega P, Baca-García E: Dual diagnosis and suicide risk in a Spanish outpatient sample. Subst Use Misuse 2012, 47:383-389.

12. Roncero C, Daigre C, Grau-López L, Rodríguez-Cintas L, Barral C, Pérez-Pazos J, Gonzalvo B, Corominas M, Casas M: Cocaine-induced psychosis in cocaine-dependent patients. J Addict Dis 2013, 32:263-273.

13. Szerman N, Martínez-Raga J, Peris L, Roncero C, Basurte I, Vega P, Ruiz P, Casas M: Rethinking dual disorders/pathology. Addict Disord Their Treat 2013, 12:1-10.

14. Arias F, Szerman N, Vega P, Mesias B, Basurte I, Morant C, Ochoa E, Poyo F, Babin F: Abuse or dependence on cannabis and other psychiatric disorders: Madrid study on dual pathology prevalence. Actas Esp Psiquiatr 2013, 41:122-129.

15. Torrens M, Rossi PC, Martinez-Riera R, Martinez-Sanvisens D, Bulbena A Psychiatric co-morbidity and substance use disorders: treatment in parallel systems or in one integrated system? Subst Use Misuse 2012, 47:1005-1014.

16. Roncero C, Barral C, Grau-Lopez L, Bachiller D, Szerman N, Casas M, Ruiz P. Protocols of dual diagnosis intervention in schizophrenia. Addict Disord Their Treat 2011, 10:131-154.

17. Farren CK, Hill KP, Weiss RD: Bipolar disorder and alcohol use disorder: a review. Curr Psychiatry Rep 2012, 14:659-666.

18. Grau-López L, Roncero C, Daigre C, Miquel L, Barral C, Collazos F, Casas M: Observational study on medications prescribed to dual-diagnosis outpatients. J Addict Med 2014, 8:84-89.

19. Kessler RC, McGonagle KA, Zhao S, Nelson CB, Hughes M, Eshleman S: Lifetime and 12-month prevalence of DSM-III-R psychiatric disorders in the United States: results National Comorbidity Survey. Archives of General Psychiatry 1994, 51:8-19.

20. Pettinati HM, O'Brien CP, Dundon WD: Current status of co-occurring mood and substance use disorders: a new therapeutic target. $\mathrm{Am} J$ Psychiatry 2013, 170:23-30.

21. Arias F, Szerman N, Vega P, Mesias B, Basurte I, Morant C, Ochoa E, Poyo F, Babin F: Madrid study on the prevalence and characteristics of 
outpatients with dual pathology in community mental health and substance misuse services. Adicciones 2013, 25:118-127.

22. Drake RE1, Xie H, MCHugo GJ, Shumway M: Three-year outcomes of long-term patients with co-occurring bipolar and substance use disorders. Biol Psychiatry 2004, 56:749-756.

23. McGovern MP, Xie H, Segal SR, Siembab L, Drake RE: Addiction treatment services and co-occurring disorders: prevalence estimates, treatment practices, and barriers. J Subst Abuse Treat 2006, 31:267-275.

24. Szerman N, Vega P, Grau-López L, Barral C, Basurte-Villamor I, Mesías B, Rodríguez-Cintas L, Martínez-Raga J, Casas M, Roncero C: Need of specific resources for patients with dual pathology in Spain: results of an observational study. J Dual Diagnosis 2014, 10:84-90.

25. Jaen-Varas D, Ribeiro WS, Whitfield J, Mari de JJ: Mental health and psychiatric care in Bolivia: what do we know? Int J Ment Health Syst 2014, 8:18.

26. Roncero C, Gómez-Baeza S, Vázquez JM, Terán A, Szerman N, Casas M, Bobes J: Perception of Spanish professionals on therapeutic adherence of dual diagnosis patients. Actas Esp Psiquiatr 2013, 41:319-327.

27. Iñiguez L, Monreal P, Sanz J, Del Valle A, Fusté J: An Integrated analysis of the perceptions of health care users, professionals, and managers in catalonia [69 paragraphs]. Forum Qual Sozialforschung / Forum: Qual Social Res 2009, 10:34. Retrieved from http://nbn-resolving.de/urn:nbn:de:0114fas0902340.

28. Hawkins EH: A tale of two systems: co-occurring mental health and substance abuse disorders treatment for adolescents. Annu Rev Psychol 2009, 60:197-227.

29. McGovern MP, Lambert-Harris C, Gotham HJ, Claus RE, Xie H: Dual diagnosis capability in mental health and addiction treatment services: an assessment of programs across multiple state systems. Adm Policy Ment Health 2014, 41:205-214.

30. Daigre C, Roncero C, Grau-López L, Martínez-Luna N, Prat G, Valero S, Tejedor R, Ramos-Quiroga JA, Casas M: Attention deficit hyperactivity disorder in cocaine-dependent adults: a psychiatric comorbidity analysis. Am J Addict 2013, 22:466-473.

31. Hofner MC, Python NV, Yersin B, Bodenmann P, Schoch M, Golay N: Local resources in management of adult victims of violence and abuse: a method of presentation and diffusion. Rev Med Suisse Romande 2002, 122:649-652.

32. Broekaert $E$, Vandevelde $S$, Soyez $V$, Yates R, Slater A: The third generation of therapeutic communities: the early development of the TC for addictions in Europe. Eur Addict Res 2006, 12:1-11.

33. Breton M, Pineault R, Levesque JF, Roberge D, Da Silva RB, Prud Homme A: Reforming healthcare systems on a locally integrated basis: is there a potential for increasing collaborations in primary healthcare? BMC Health Serv Res 2013, 13:262.

doi:10.1186/1752-4458-8-35

Cite this article as: Roncero et al:: Professionals' perceptions about healthcare resources for co-occuring disorders in Spain. International Journal of Mental Health Systems 2014 8:35.

\section{Submit your next manuscript to BioMed Central and take full advantage of:}

- Convenient online submission

- Thorough peer review

- No space constraints or color figure charges

- Immediate publication on acceptance

- Inclusion in PubMed, CAS, Scopus and Google Scholar

- Research which is freely available for redistribution

Submit your manuscript at www.biomedcentral.com/submit 